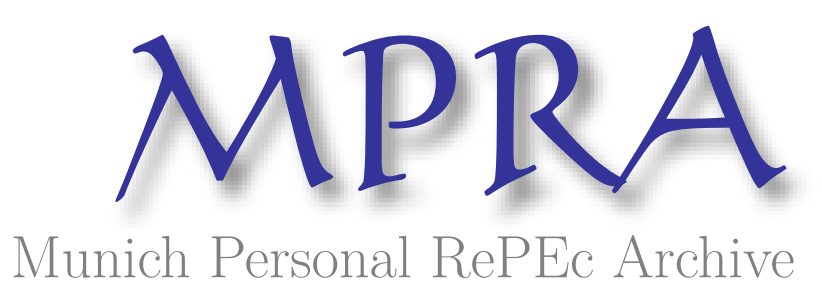

\title{
Special Interest Politics and Intellectual Property Rights: An Economic Analysis of Strengthening Patent Protection in the Pharmaceutical Industry
}

\author{
Chu, Angus C. \\ University of Michigan
}

August 2007

Online at https://mpra.ub.uni-muenchen.de/4349/

MPRA Paper No. 4349, posted 03 Aug 2007 UTC 


\title{
Special Interest Politics and Intellectual Property Rights:
}

\section{An Economic Analysis of Strengthening Patent Protection in the Pharmaceutical Industry}

\author{
Angus C. Chu* \\ University of Michigan
}

August 2007

\begin{abstract}
Since the 80's, the pharmaceutical industry has benefited substantially from a series of policy changes that have strengthened the patent protection for brand-name drugs as a result of the industry's political influence. This paper incorporates special interest politics into a quality-ladder model to analyze the policymakers' tradeoff between the socially optimal patent length and campaign contributions. The welfare analysis suggests that the presence of a pharmaceutical lobby distorting patent protection is socially undesirable in a closed-economy setting but may improve social welfare in a multi-country setting, which features an additional efficiency tradeoff between monopolistic distortion and international free-riding on innovations.
\end{abstract}

Keywords: campaign contributions, intellectual property rights, patent length, special interest politics JEL classification: D72, O31, O34

\footnotetext{
* Department of Economics, University of Michigan, 611 Tappan St., Ann Arbor, MI 48109, USA. Email address: angusccc@umich.edu. I am truly indebted to Dmitriy Stolyarov for his guidance and patience. I am grateful to Chris House, John Laitner, Linda Tesar and Rosemarie Ziedonis for invaluable advice and to Oli Coibion, Osborne Jackson, Stephan Lindner, Zoe Mclaren, Ryan Michaels, Jing Zhang and workshop participants at the University of Michigan for helpful suggestions. I am especially thankful to Devashish Mitra (the Editor) and the anonymous referee for insightful and detailed comments that have greatly improved the manuscript and to Robert Barro for journal recommendation. All errors are, of course, mine.
} 
"What's true of the eight-hundred-pound gorilla is true of the colossus that is the pharmaceutical industry. It is used to doing pretty much what it wants to do." - Marcia Angell (2005, p. 3)

\section{INTRODUCTION}

Since the 80 's, the pharmaceutical industry has benefited substantially from a series of laws enacted by the Congress, such as the Bayh Dole Act in 1980, ${ }^{1}$ the Hatch-Waxman Act in $1984,{ }^{2}$ the Prescription Drug User Fee Act of 1992, ${ }^{3}$ and the Food and Drug Administration Modernization Act of $1997 .{ }^{4}$ These policies result in an extension of the commercial lifetime of patents for brand-name drugs. ${ }^{5}$ So, why did the government implement all these policy changes?

At the first glance, the answer could be quite obvious that there must be incentives for the policymakers to do so. But, the real puzzle is about what exactly these incentives are. It may be the case that the government has the incentives to act as a social planner and to maximize social welfare as we, economists, usually like to assume. However, the reality is neither so simple nor ideal. Douglass North (2005, p. 67) describes the incentives of the government as,

"The Government is not a disinterested party in the economy. By the very nature of the political process..., the government has strong incentives to behave opportunistically to

\footnotetext{
${ }^{1}$ The Bayh-Dole Act essentially allows universities and other non-profit institutions to patent discoveries from publicly funded medical research and then to grant exclusive licenses to drug companies. See, e.g. Jaffe (2000), Eisenberg (2001) and Angell (2005, chapter 1).

${ }^{2}$ The Hatch-Waxman Act enables drug companies to extend monopoly rights by restoring up to five years of lost patent time on premarket testing and the Food and Drug Administration (FDA) approval process. See, e.g. Eisenberg (2001) and Gallini (2002). Also, as a result of this Act, “...if a brand-name company sues a generic company for patent infringement, FDA approval of the generic drug will automatically be delayed for [up to] thirty months... In effect, the FDA will add thirty months to the brand-name drug's exclusivity." Angell (2005, p. 179-180)

${ }^{3}$ The Prescription Drug User Fee Act of 1992 authorizes the FDA to collect user fees from the pharmaceutical industry and at the same time requires the FDA to significantly reduce its approval time for drugs. As a result, the FDA approval time decreases from 2.6 years to 1.4 years, which in turn increases the commercial lifetime of patents for drugs. See, e.g. NIHCM (2000).

${ }^{4}$ The Food and Drug Administration Modernization Act of 1997 extends the monopoly rights for a drug by six months if it is tested in children. "The result is that drug companies now test their blockbusters, including drugs to treat primarily adult diseases like high blood pressure, in children, just because the extra protection is so lucrative." Angell (2005, p. 182)

${ }^{5}$ Refer to Table 2 for details. The commercial lifetime of patent for a drug refers to the number of years remaining in the drug's patent term after clinical testing and FDA's approval of the drug.
} 
maximize the rents of those with access to the government decision-making process... [I]t means that the government will cartelize economic activity in favor of politically influential parties. In rare cases the government designs and enforces a set of rules of the game that encourage productive activity."

The $\$ 200$-billion industry not only has access to the government's decision-making process, ${ }^{6}$ but it is indeed so politically influential that "PhRMA [the Pharmaceutical Research and Manufacturers of America], this lobby, has a death grip on Congress", in the words of Senator Richard J. Durbin. ${ }^{7}$ This political influence potentially comes from the impressive amount of the industry's lobbying expenditures and campaign contributions. For example, the industry's total expenditure on lobbying from 1998 to 2006 was $\$ 1,087$ million, and total campaign contributions amount to $\$ 139$ million during the election cycles from 1990 to $2006 .{ }^{8}$ In fact, given the nature of the industry, it is easy to understand that it is in the drug companies' best interest to have access to the policymakers, who can easily return favors at low political costs. For a blockbuster (a drug that has sales of over a billion dollars a year), an extension of the patent's effective lifetime for a few years could be extremely profitable given the usually negligible marginal cost of production for drugs.

The purpose of this paper is to provide a theoretical analysis on this phenomenon by taking as a premise the hypothesis that campaign contributions are for the purpose of buying legislative influence. In particular, it incorporates special interest politics into a quality-ladder growth model to analyze the political-economic tradeoff facing the policymakers, who have to balance between the optimal level of patent protection to maximize social welfare on one hand and the interests of the special interest group

\footnotetext{
${ }^{6}$ The figure of $\$ 200$ billion refers only to how much Americans spent on prescription drugs in 2002, and it does not include the other large expenses on drugs administered in hospitals, nursing homes, or doctors' offices. Combining all these expenses, the industry's revenue is roughly $\$ 400$ billions in 2002. See, e.g. Angell (2005, p. 4-5).

${ }^{7}$ Robert Pear, "Drug Companies Increase Spending on Efforts to Lobby Congress and Governments" New York Times, June 1, 2003.

${ }^{8}$ These two figures are quoted in nominal terms. Refer to Table 1 for the detailed breakdown in real terms.
} 
(SIG) in exchange for campaign contributions on the other. ${ }^{9}$ It is analytically shown that the government placing a higher value on campaign contributions increases: (a) the patent length; (b) the amount of monopolistic profits; (c) the market value of patents; and (d) R\&D investments. These results are consistent with the data in Section 2. Furthermore, this paper derives a unique level of the government's bargaining power above which the amount of campaign contributions increases with respect to the weight that the government places on campaign contributions.

In terms of welfare implications, it is not surprising and perhaps trivial that the presence of a SIG lobbying the government to distort the level of patent protection is socially undesirable in a closedeconomy setting. However, in a multi-country setting, the presence of a SIG lobbying its own government in each country may improve social welfare because the level of patent protection in the multi-country Nash equilibrium without lobbying is suboptimally low due to the positive externality of international spillovers in innovations suggested by previous studies, such as Grossman and Lai (2004) and Lai and Qiu (2003). Therefore, the multi-country political equilibrium features an additional efficiency tradeoff between monopolistic distortion and the detrimental effects of international free-riding on innovations, and the finding of potential welfare gains arises from the SIGs increasing the level of patent protection from a globally suboptimal level and acting as an externality-correcting device. In addition, the pharmaceutical lobby may even improve the welfare of the consumers, who do not own any patent, when the degree of international free-riding on innovations is severe enough. Finally, this paper shows that if the SIGs have asymmetric influences across countries, then the country, in which the government places a higher value on campaign contributions, would gain by less or even suffer a welfare loss.

This paper relates to four strands of literature: (a) political economy of trade policy, (b) political economy and economic growth; (c) the welfare effects of lobbying; and (d) international patent protection. Feenstra (2004, chapter 9) provides a comprehensive discussion on the political economy of trade policy. An elegant formulation of special interest politics and trade policy is provided by Grossman

\footnotetext{
${ }^{9}$ This setup is motivated by Grossman and Helpman's (2002, p. 5) insight that “[p]oliticians value contributions for their potential usefulness in financing campaigns, but many also wish to enact policies that benefit the public in order to improve their popularity among the well informed or to fulfill their sense of social responsibility."
} 
and Helpman (1994), who later develop a set of modeling tools on special interest politics in Grossman and Helpman (2001), from which this paper borrows to analyze patent policy. Drazen (2000, chapter 11) and Persson and Tabellini (2000, chapter 14) provide a comprehensive discussion on political economy and economic growth. The literature has so far focused on the relations between economic growth and a number of issues, such as income inequality through redistributive policies, political institutions through property rights, and the adoption of new technology through the distribution of technological-vintagespecific human capital. This paper provides a theoretical analysis on economic growth and the political economy of patent policy on one hand and analyzes the welfare effects of lobbying on the other. Recent studies on the welfare effects of lobbying, such as Besley and Coate (2001) and Coate and Morris (1999), analyze the negative effects of lobbying on social welfare arising from coordination failures between multiple SIGs, the excessive entry of citizens into running for office, and the implementation of Pareto dominated policies due to the fear of lobbying-driven hysteresis in policy decisions.

In the literature on international patent protection, Grossman and Lai (2004) and Lai and Qiu (2003) analyze the welfare effects of strengthening patent protection in developing countries as a result of the TRIPS agreement using a multi-country variety-expanding growth model. In contrast, the current paper develops a multi-country quality-ladder growth model to analyze international patent protection and the political-economy aspects of patent policy. Dinopoulous et al (2005) analyze international patent protection using a North-South quality-ladder model. In their model, the level of patent protection is an exogenous parameter, and they are interested in the effects of patent protection on long-run growth and technology transfer; on the other hand, in the current paper, the level of patent protection is a policy instrument chosen by the government to maximize its objective function. Furthermore, the current paper incorporates special interest politics into the growth model to analyze the welfare implications of a pharmaceutical lobby. Lai (2005) extends the variety-expanding model in Grossman and Lai (2004) to analyze the effects of political contributions on the level of patent protection and shows insufficient patent protection prior to the TRIPS agreement. The current paper complements and extends Lai (2005) by taking insufficient patent protection as a starting point and by investigating whether the increasing 
political influence of the pharmaceutical lobby has improved social welfare. In addition, the current paper considers the welfare implications under both symmetric and asymmetric SIGs.

Before closing the introduction, I briefly discuss two common critiques against the hypothesis of campaign contributions as political investments. The first one is the small amount of campaign contributions relative to the potential financial returns at stake. Helpman and Persson (2001) provide an interesting model to show that a small amount of contributions does not necessarily imply that it has no effects on policy outcomes. In their model, lobbying has important influences on policy outcomes and the equilibrium amount of contributions is as small as zero because of the competition between legislators. The other common critique is that individuals are the main source of money in US campaigns. Based on this observation, Ansolabehere et al (2003) argue that campaign contributions should be considered as consumption goods rather than political investments. However, this argument does not rule out the possibility that SIGs contribute in order to influence the policymakers on certain policies. Ansolabehere $e t$ al (2003) write, “[a]lthough aggregate campaign expenditures primarily reflect consumption, it may be that a subset of donors, mainly corporate and industry PACs [political action committees], behave as if they expected favors in return. These contributors may in fact receive a reasonable rate of return - say 20 percent..."

The rest of this paper is organized as follows. Section 2 provides some stylized facts about the pharmaceutical industry. Section 3 describes the model and presents the theoretical results. The final section concludes. Some of the proofs are contained in Appendix A.

\section{SOME STYLIZED FACTS ABOUT THE PHARMACEUTICAL INDUSTRY}

Table 1 indicates that the industry spends a large amount of money on lobbying each year and on campaign contributions during each election cycle. Another feature of the data is that lobbying expenditures in real terms have been rising rapidly at an average annual growth rate of $9.96 \%$. Proposition

2 suggests that this rising trend may be interpreted as an indication for the increasing importance of lobbying and campaign contributions that motivate the comparative static exercise in Section 3. 


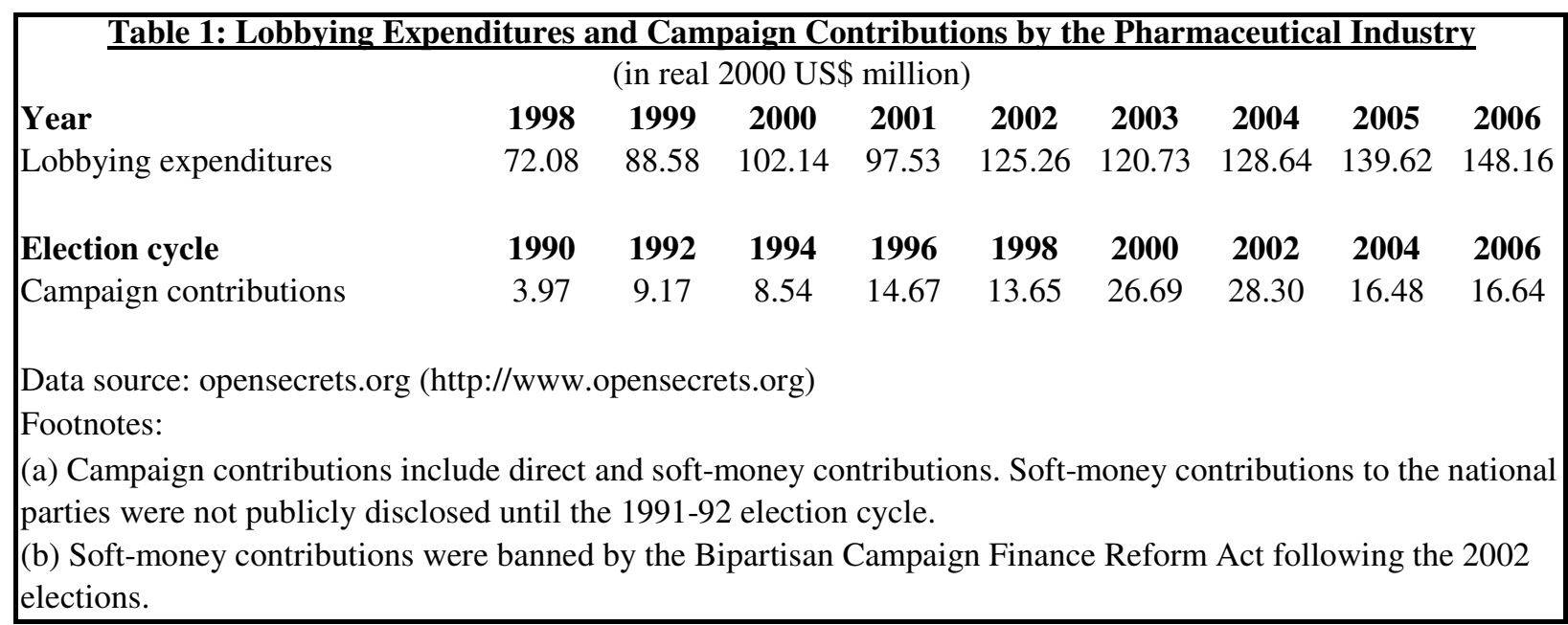

Table 2 presents the details of the extension in the commercial lifetime of patent and market exclusivity for drugs as a result of the policy changes during the 80 's and 90's. Note that the effects captured in Table 2 underestimates the true extension of monopoly rights for brand-name drugs because they do not take into account the fact that the companies could strategically utilize the market exclusivity provided by the Hatch-Waxman Act to protect a new generation of slightly-modified products. ${ }^{10}$

\begin{tabular}{|lc|}
\hline \multicolumn{2}{|c|}{ Table 2: Extension in Commercial Lifetime of Patents and Market Exclusivity for Drugs } \\
Hatch-Waxman & Number of Years Added \\
PDUFA & +2.3 years \\
URAA & +2.1 years \\
FDAMA & +1 year \\
& +0.5 year \\
Source: NIHCM (2000) & \\
Footnotes: & \\
(a) Hatch-Waxman: The Drug Competition and Patent Term Restoration Act of 1984 \\
(b) PDUFA: The Prescription Drug User Fee Act of 1992 \\
(c) URAA: The Uruguay Round Agreements Act of 1994 \\
(d) FDAMA: The Food and Drug Administration Modernization Act of 1997 \\
\hline
\end{tabular}

To summarize, the data presented so far is consistent with the hypothesis that the pharmaceutical industry has successfully exercised its political power, which comes from lobbying and campaign contributions, to influence the policymakers in order to strengthen patent protection for brand-name drugs. The next question is whether these policy changes have led to handsome financial returns for the industry.

\footnotetext{
${ }^{10}$ From NIHCM (2000), “... if a manufacturer timed the introduction of a new use, such as a more convenient dosing form, to coincide with the expiration of the 'mother' drug's patent, it could have shielded the 13.9 to 15.4 years franchise of the drug for an additional three years, for as long as 17 to 18 years overall."
} 
Indeed, they have. As Angell (2005, p. 3) writes, “[t]he watershed year was 1980. Before then, it was a good business, but afterward, it was a stupendous one.” Table 4 presents some financial time series for the top 10 pharmaceutical companies in Fortune 500 as an example. Each number in the table represents the annual average of the combined figures of the companies; for example, the first row presents the annual averages of the combined sales of the companies in the last decades. The data indicates that both sales and pretax income have been rising at a faster rate than the real GDP. Also, as a result of the stronger patent protection, the market value of pharmaceutical patents should have increased as well. A rough proxy for the value of patents owned by the companies is the value of intangible assets, ${ }^{11}$ which has also risen substantially.

\begin{tabular}{|c|c|c|c|c|}
\hline \multicolumn{5}{|c|}{$\frac{\text { Table 3: Financial Figures of the Top 10 Pharmaceutical Comp }}{\text { (in real } 2000 \text { US } \$ \text { million) }}$} \\
\hline 1960-69 & $1970-79$ & 1980-89 & 1990-99 & 2000-05 \\
\hline Sales & & & 6 & \\
\hline Pretax Income & 6,051 & 9,132 & 23,376 & \\
\hline tangible Assets & & 2,918 & & \\
\hline \multicolumn{5}{|c|}{$\begin{array}{l}\text { Data source: COMPUSTAT North America } \\
\text { Footnotes: } \\
\text { (a) According to CNNMoney.com, the Top } 10 \text { companies in } 2006 \text { are: Abbott Laboratories, Amgen, Bristol-Myers } \\
\text { Squibb, Eli Lilly, Forest Laboratories, Johnson \& Johnson, Merck, Pfizer, Schering-Plough, and Wyeth. } \\
\text { (b) The figures do not include the data for Amgen because it does not have a complete time series for the above } \\
\text { years. } \\
\text { (c) For J\&J, Eli Lilly, Pfizer, and Schering-Plough, intangible assets include both intangible assets and other assets } \\
\text { because intangible assets were included in other assets for some years. }\end{array}$} \\
\hline
\end{tabular}

Motivated by the data presented above, the theoretical model in Section 3 attempts to achieve the following analytical results to confirm the basic intuition of the model. An increase in the value that the government places on campaign contributions in its objective function should lead to an extension in the patent length for brand-name drugs, and consequently an increase in the amount of monopolistic profits generated by the industry and the market value of patents. In addition, the model predicts that $R \& D$ investments on pharmaceuticals would increase. Table 4 shows that this is also true in the data. Private

\footnotetext{
${ }^{11}$ This proxy is a rough approximation at best for two reasons: (a) it includes other items, such as trade secrets, trademarks, and goodwill; and (b) the accounting valuation methods may not accurately reflect the market value.
} 
$\mathrm{R} \& \mathrm{D}$ spending on drugs in real terms has been increasing at an average annual growth rate of $7.28 \%$ since the 80 's.

\begin{tabular}{|c|c|c|c|c|c|c|c|c|c|c|}
\hline \multicolumn{11}{|c|}{ Table 4: Private R\&D Spending on Phamaceuticals and Medicines } \\
\hline \multicolumn{11}{|c|}{ (in real 2000 US\$ million) } \\
\hline 1981 & 1982 & 1983 & 1984 & 1985 & 1986 & 1987 & 1988 & 1989 & 1990 & 1991 \\
\hline 3,494 & 3,946 & 4,445 & 4,897 & 4,997 & 5,135 & 5,595 & 6,473 & 7,015 & 7,251 & 8,225 \\
\hline 1992 & 1993 & 1994 & 1995 & 1996 & 1997 & 1998 & 1999 & 2000 & 2001 & 2002 \\
\hline 9,182 & 10,332 & 10,664 & 11,078 & 10,410 & 12,143 & 13,025 & 12,502 & 12,854 & 9,899 & 13,614 \\
\hline
\end{tabular}

\section{A QUALITY-LADDER GROWTH MODEL WITH SPECIAL INTEREST POLITICS}

The quality-ladder growth model originates from Aghion and Howitt (1992) and Grossman and Helpman (1991), in which scale effects are eliminated by assuming decreasing individual R\&D productivity as in Segerstrom (1998). ${ }^{12}$ The basic framework is modified to introduce: (a) patent protection in the form of patent length; and (b) an organized SIG representing the owners of pharmaceutical patents. The model is further modified to include homogenous goods and quality-enhancing goods (i.e. pharmaceuticals).

Sections $3.1-3.4$ firstly present the different components of the model in a closed-economy setting, and then the decentralized equilibrium is defined in Section 3.5. After characterizing the socially optimal patent length, lobbying is incorporated into the model by assuming that the government values campaign contributions in addition to social welfare. As a result, the SIG is able to distort the level of patent protection to benefit itself. The comparative static result shows that an increase in the importance of campaign contributions in the government's objective function increases: (a) the patent length; (b) the amount of monopolistic profits; (c) the market value of patents; and (d) R\&D investments. Finally, the different welfare implications of lobbying are derived under the closed-economy and multi-country settings with symmetric and asymmetric SIGs.

\footnotetext{
${ }^{12}$ See, e.g. Jones (1995a) and Jones (1999) for a discussion of scales effects in R\&D-driven endogenous growth models. After eliminating scale effects, the resulting model becomes the so-called semi-endogenous growth model, in which the growth rate along the balanced-growth path is proportional to the labor-force growth rate. An increase in the share of R\&D workers raises the level of technology while holding its balanced-growth rate constant.
} 


\subsection{HOUSEHOLDS}

There is a continuum of households indexed by $i \in[0,1]$, and their lifetime utility function is

$$
U(i)=\int_{0}^{\infty} e^{-(\rho-n) t}\left(c_{h, t}(i)+\beta \ln c_{q, t}(i)\right) d t .^{13}
$$

$c_{h, t}(i)$ is the per capita consumption of homogenous goods, and it is chosen as the numeraire. $\beta$ is a preference parameter reflecting the importance of the per capita consumption of quality-enhancing goods, denoted by $c_{q, t}(i)$. Each household has $L_{t}=e^{n . t}$ members at time $t$, and $n>0$ is the exogenous population growth rate. $\rho$ is the subjective discount rate. To ensure that utility is bounded,

$$
\rho>n
$$

Each household maximizes utility subject to a sequence of budget constraints

$$
\dot{a}_{t}(i)=\left(r_{t}-n\right) a_{t}(i)+w_{t}-c_{h, t}(i)-P_{q, t} c_{q, t}(i) .
$$

Each member of a household inelastically supplies one unit of homogenous labor in each period to earn a wage income $w_{t} . r_{t}$ is the real rate of return on the financial assets, which represent the market value of patents in equilibrium. Each household $i \in[0,1]$ belongs to either of two types $\in\{I, I I\}$. Type-I household $i \in[0, \theta]$ and Type-II household $i \in(\theta, 1]$ differ in their investment opportunity sets.

Assumption 1: Type-I households have access to the financial market while Type-II households are restricted from participating in the financial market such that $a_{t}(I I)=0 .{ }^{14}$

\footnotetext{
${ }^{13}$ The quasi-linear preference enables me to derive the patent length in the political equilibrium with a minimal assumption of efficient bargaining between the government and the SIG.

${ }^{14}$ In this setting, the identity of the two types of households is exogenously imposed. In fact, this identity can be endogenously derived by assuming an exogenous difference in the discount rates across the two types of households along with a borrowing constraint. Then, the households who have a lower discount rate would be the owners of financial assets in equilibrium.
} 
This setup leads to a conflict of interest between the patent owners (i.e. Type-I households) who benefit from an increase in the rate of return on $\mathrm{R} \& \mathrm{D}$ investments and the consumers (i.e. Type-II households) who don't, and this conflict of interest gives rise to the importance of political economics.

From Type-I households' intertemporal optimization, the Euler equation derived from the quasilinear preference equates the rate of return on financial assets to the subjective discount rate such that

$$
r_{t}=\rho
$$

The intratemporal optimality condition determines the amount of spending on the quality-enhancing goods in each period to be

$$
P_{q, t} c_{q, t}(i)=\beta
$$

for $i \in\{I, I I\}$. Since both types of households consume the same amount of quality-enhancing goods, notation simplifies to $c_{q, t} \equiv c_{q, t}(i)$. Aggregate consumption of pharmaceuticals $C_{q, t}=L_{t} c_{q, t}$ is a standard Cobb-Douglas aggregator of a continuum of differentiated quality-enhancing intermediate goods $j \in[0,1]$ (i.e. differentiated drugs). The production function is given by

$$
Y_{q, t}=\exp \left(\int_{0}^{1} \ln Y_{q, t}(j) d j\right)
$$

and the familiar aggregate price index is

$$
P_{q, t}=\exp \left(\int_{0}^{1} \ln P_{q, t}(j) d j\right)
$$

The first-order condition for differentiated drug $j \in[0,1]$ is

$$
P_{q, t}(j) Y_{q, t}(j)=P_{q, t} C_{q, t}
$$

\subsection{HOMOGENOUS GOODS}

There exists a larger number of competitive firms producing the homogenous goods $Y_{h, t}$. The production function has constant returns to scale in labor input $L_{h, t}$ given by 


$$
Y_{h, t}=\alpha L_{h, t}
$$

The marginal cost of production is

$$
M C_{h, t}=w_{t} / \alpha
$$

Since the homogenous goods are chosen to be the numeraire and this sector is characterized by marginalcost pricing, the marginal cost is also one. Therefore, the real wage is given by $w_{t}=\alpha$, and the marketclearing condition is

$$
Y_{h, t}=C_{h, t}=L_{t}\left(\theta c_{h, t}(I)+(1-\theta) c_{h, t}(I I)\right)
$$

where $C_{h, t}$ is the total consumption of homogenous goods.

\subsection{THE PHARMACEUTICAL INDUSTRY}

Within the pharmaceutical industry, there is a continuum of sub-industries on the unit interval producing differentiated drugs. Each sub-industry $j \in\left[0, \omega_{t}\right]$ is dominated by a temporary monopolistic leader, who holds a valid patent on the latest technology, and each sub-industry $j \in\left(\omega_{t}, 1\right]$ is characterized by perfect competition because the most recent patent has expired. $\omega_{t}$ is endogenously determined by the patent length chosen by the government. The following formulation of patent length is originally developed by Grossman and Lai (2004) for a variety-expanding model and subsequently modified by Dinopoulos et al (2005) for a quality-ladder model. In standard quality-ladder models, a patent's effective lifetime ends when a higher level of technology is invented in the same industry. As in Dinopoulos et al (2005), I assume that a monopolistic leader can maintain its monopoly position until the end of the statutory patent life, denoted by $T$. This assumption is especially relevant for the pharmaceutical industry, in which the effective patent life for drugs usually coincides with the statutory patent life. ${ }^{15}$

\footnotetext{
${ }^{15}$ In this case, the statutory patent life refers to the patent length granted by the US Patent and Trademark Office as well as the length of exclusive marketing rights granted by the FDA.
} 
Assumption 2: Entrepreneurs can only invest in $R \& D$ to develop a better drug after the latest patent in the sub-industry has expired.

When a patent expires, the monopolistic sub-industry temporarily becomes a generic sub-industry characterized by marginal-cost pricing until the next innovation occurs. Therefore, extending the statutory patent life has two opposing effects on social welfare. On one hand, it enhances the incentives for R\&D by raising the present value of the stream of profits earned by a monopolistic leader. On the other hand, it increases the dead weight loss by increasing the fraction of monopolistic sub-industries due to a longer period of patent protection. At the constrained social optimum, the government balances these opposing effects to maximize social welfare.

The production function in sub-industry $j$ is

$$
Y_{q, t}(j)=z^{m_{t}(j)} L_{q, t}(j)
$$

$L_{q, t}(j)$ is the number of workers hired by sub-industry $j$ at time $t . z^{m_{t}(j)}$ is the monopolistic leader's marginal product of labor, which is increasing over time due to technological improvement. $z>1$ is the exogenous step-size of productivity improvement arising from each innovation. $m_{t}(j)$, which is an integer, is the number of innovations that has occurred in sub-industry $j$ as of time $t$. The marginal cost of production is

$$
M C_{q, t}(j)=w_{t} / z^{m_{t}(j)}
$$

For a monopolistic sub-industry $j \in\left[0, \omega_{t}\right]$, the price-setting behavior is governed by the closet rival's marginal cost of production $w_{t} / z^{m_{t}(j)-1}$. The familiar Bertrand-equilibrium price is

$$
P_{q, t}(j)=z M C_{q, t}(j)=z \alpha / z^{m_{t}(j)}
$$

Thus, the monopolistic leader charges a markup of $z$ over the marginal cost, and the equilibrium profit is

$$
\pi_{q, t}(j)=(z-1) M C_{q, t}(j) Y_{q, t}(j)=(z-1) \alpha L_{q, t}(j) \text {. }
$$


In equilibrium, $L_{q, t}(j)$ is the same across $j \in\left[0, \omega_{t}\right]$ because of the Cobb-Douglas specification in (5), so that $\pi_{q, t}(j)$ is also the same across $j \in\left[0, \omega_{t}\right]$.

Substituting (11) into (5), the aggregate production function for pharmaceuticals becomes

$$
Y_{q, t}=A_{t} L_{q, t}^{e}
$$

$L_{q, t}^{e}=\exp \left(\int_{0}^{1} \ln L_{q, t}(j) d j\right)$ is an index of effective labor inputs, ${ }^{16}$ and $A_{t}=\exp \left(\int_{0}^{1} m_{t}(j) d j \ln z\right)$ is the aggregate level of technology for pharmaceuticals. Without loss of generality, the sub-industries are ordered such that $j$ is monopolistic for $j \in\left[0, \omega_{t}\right]$ and $j^{\prime}$ is generic for $j^{\prime} \in\left(\omega_{t}, 1\right]$. Substituting (13) into (6), the aggregate price index for pharmaceuticals becomes

$$
P_{q, t}=z^{\omega_{t}} \alpha / A_{t}
$$

Substituting (16) into (4) and multiplying by $L_{t}$, aggregate consumption of pharmaceuticals becomes

$$
C_{q, t}=\left(A_{t} / z^{\omega_{t}}\right)\left(\beta L_{t} / \alpha\right)
$$

$C_{q, t}$ decreases in $\omega_{t}$ reflecting the markup-pricing distortion and increases over time due to $A_{t}$ reflecting technological improvements. Using (15) and (17), the index of effective labor inputs becomes $L_{q, t}^{e}=\beta L_{t} /\left(z^{\omega_{t}} \alpha\right)$. The first-order condition from (7) implies that the ratio of relative labor inputs in the monopolistic and generic sub-industries is $L_{q, t}\left(j^{\prime}\right) / L_{q, t}(j)=z$. Therefore, the index of effective labor inputs can be re-expressed as $L_{q, t}^{e}=z^{1-\omega_{t}} L_{q, t}(j)$, and the number of workers in monopolistic sub-industry $j$ is $L_{q, t}(j)=\beta L_{t} /(z \alpha)$. Substituting this condition into (14) yields

$$
\pi_{q, t}(j)=\left(\frac{z-1}{z}\right) \beta L_{t}
$$

\footnotetext{
${ }^{16}$ This index is different from the actual number of workers in the pharmaceutical industry because the number of workers varies across sub-industries in the present model as a result of the presence of both monopolistic and generic sub-industries.
} 
which is the same across all monopolistic sub-industries and increases over time as the total population grows. The total amount of monopolistic profit is

$$
\pi_{q, t}=\int_{0}^{\omega_{t}} \pi_{q, t}(j) d j=\omega_{t}\left(\frac{z-1}{z}\right) \beta L_{t} .
$$

Finally, the actual number of workers employed in the pharmaceutical industry is

$$
L_{q, t}=\omega_{t} L_{q, t}(j)+\left(1-\omega_{t}\right) L_{q, t}\left(j^{\prime}\right)=\left(\frac{\omega_{t}+\left(1-\omega_{t}\right) z}{z}\right) \frac{\beta L_{t}}{\alpha}
$$

which increases over time at the population growth rate.

\subsection{R\&D}

The no-arbitrage value of a pharmaceutical patent $V_{t}$ for a new successful innovation at time $t$ is the present value of the stream of profits earned by the R\&D entrepreneur who becomes the next industry leader until the patent expires. From (19),

$$
V_{t}=\int_{\tau=t}^{t+T} e^{-\rho(\tau-t)} \pi_{q, \tau}\left(j^{\prime}\right) d \tau=\frac{\Omega(T)}{\rho-n}\left(\frac{z-1}{z}\right) \beta L_{t}
$$

where $\Omega(T) \equiv 1-\exp (-(\rho-n) T)$ has the properties of $\Omega(0)=0, \Omega(\infty)=1$, and $\Omega^{\prime}(T)>0$.

The Poisson arrival rate $\lambda_{t}(k)$ of a successful innovation for an $\mathrm{R} \& \mathrm{D}$ entrepreneur $k \in[0,1]$ is a function of labor inputs given by

$$
\lambda_{t}(k)=\bar{\varphi}_{t} L_{r, t}(k)
$$

where $\bar{\varphi}_{t}$ is the individual $\mathrm{R} \& \mathrm{D}$ productivity parameter that the entrepreneur takes as given. The $\mathrm{R} \& \mathrm{D}$ sector is characterized by constant returns to scale and perfect competition. The expected profit earned by entrepreneur $k$ is

$$
\pi_{r, t}(k)=V_{t} \lambda_{t}(k)-w_{t} L_{r, t}(k)
$$

The first-order condition is 


$$
V_{t} \bar{\varphi}_{t}=\alpha
$$

which is the key condition that determines the number workers allocated to the R\&D sector.

To eliminate scale effects, the individual R\&D productivity parameter $\bar{\varphi}_{t}$ at time $t$ is assumed to be decreasing in the level of technology $A_{t}$ such that

$$
\bar{\varphi}_{t}=\frac{\varphi L_{r, t}^{\gamma-1}}{A_{t}^{1-\phi}}
$$

where $L_{r, t}=\int_{0}^{1} L_{r, t}(k) d k . \phi \in(-\infty, 1)$ captures the externality of intertemporal knowledge spillovers, ${ }^{17}$ and $\gamma \in(0,1]$ captures the intratemporal negative congestion externality or the so-called "stepping on toes" effects. The law of motion for pharmaceutical technology is

$$
\dot{A}_{t}=A_{t} \lambda_{t} \ln z=A_{t} \bar{\varphi}_{t} L_{r, t} \ln z=A_{t}^{\phi} L_{r, t}^{\gamma} \varphi \ln z .^{18}
$$

\subsection{DECENTRALIZED EQUILIBRIUM}

The equilibrium is a sequence of prices $\left\{w_{t}, r_{t}, V_{t}, P_{q, t}(j), M C_{q, t}(j)\right\}_{t=0}^{\infty}$ and a sequence of allocations $\left\{a_{t}(I), c_{h, t}(i), c_{q, t}(i), Y_{q, t}(j), L_{q, t}(j), L_{r, t}(k), L_{h, t}\right\}_{t=0}^{\infty}$ that are consistent with the initial conditions $\left\{L_{0}, A_{0}, \bar{\varphi}_{0}\right\}$ and their subsequent laws of motions. Also,

(a) each Type-I household chooses $\left\{a_{t}(I), c_{h, t}(I), c_{q, t}(I)\right\}$ and supplies labor to maximize utility taking $\left\{w_{t}, r_{t}, P_{q, t}(j)\right\}$ as given;

\footnotetext{
${ }^{17}$ As discussed in Jones (1995b), $\phi \in(0,1)$ corresponds to the "standing on shoulder" effect, in which aggregate R\&D productivity $A_{q} \bar{\varphi}$ increases as the level of technology increases (see the law of motion for technology). On the other hand, $\phi \in(-\infty, 0)$ corresponds to the "fishing out" effect, in which early technology is relatively easy to develop and $A_{q} \bar{\varphi}$ decreases as the level of technology increases.

${ }^{18}$ This expression is derived as $\ln A_{t}=\left(\int_{0}^{1} \ln z^{m_{t}(j)} d j\right)=\left(\int_{0}^{1} m_{t}(j) d j\right) \ln z=\left(\int_{0}^{t} \lambda(\tau) d \tau\right) \ln z$; then, differentiation with respect to time yields $\dot{A}_{t} / A_{t}=\lambda_{t} \ln z$.
} 
(b) each Type-II household chooses $\left\{c_{h, t}(I I), c_{q, t}(I I)\right\}$ and supplies labor to maximize utility taking $\left\{w_{t}, P_{q, t}(j)\right\}$ as given;

(c) competitive firms in the homogenous-goods sector chooses $\left\{L_{h, t}\right\}$ to maximize profits according to the production function taking $\left\{w_{t}\right\}$ as given;

(d) each monopolistic leader in pharmaceutical sub-industry $j \in\left[0, \omega_{t}\right]$ chooses $\left\{P_{q, t}(j), L_{q, t}(j)\right\}$ to maximize profits according to the Bertrand price competition and its production function taking $\left\{M C_{q, t}(j), Y_{q, t}(j)\right\}$ as given;

(e) competitive firms in pharmaceutical sub-industry $j \in\left(\omega_{t}, 1\right]$ choose $\left\{L_{q, t}(j)\right\}$ to maximize profits according to the production function taking $\left\{P_{q, t}(j), M C_{q, t}(j), Y_{q, t}(j)\right\}$ as given;

(f) each entrepreneur $k \in[0,1]$ in the $\mathrm{R} \& \mathrm{D}$ sector chooses $\left\{L_{r, t}(k)\right\}$ to maximize profits according to the production function taking $\left\{w_{t}, V_{t}, \bar{\varphi}_{t}\right\}$ as given;

(g) The market for the homogenous goods clears such that $Y_{h, t}=C_{h, t}$;

(h) The market for pharmaceuticals clears such that $Y_{q, t}=C_{q, t}$; and

(i) The labor market clears such that $L_{h, t}+L_{q, t}+L_{r, t}=L_{t}$.

\subsection{BALANCED-GROWTH PATH}

Along the balanced-growth path, $L_{r, t}$ increases at the population growth rate (to be shown below). Therefore, the balanced-growth rate of technology for pharmaceuticals denoted by $g$ must be proportional to the population growth rate such that

$$
g \equiv \frac{\dot{A}_{t}}{A_{t}}=\frac{L_{r, t}^{\gamma}}{A_{t}^{1-\phi}} \varphi \ln z=\frac{\gamma}{1-\phi} n
$$


Then, the steady-state Poisson arrival rate of innovations is $\lambda=g / \ln z$. The fraction of monopolistic sub-industries at time $t$ is the sum of all inventions from the last $T$ periods

$$
\omega_{t}=\int_{0}^{T} \lambda_{t-\tau} d \tau
$$

Therefore, the steady-state value of $\omega$ is simply $T \lambda$. To ensure that $\omega \in(0,1]$, an upper bound given by

$$
T \leq 1 / \lambda=\frac{(1-\phi) \ln z}{n \gamma}
$$

is imposed on the patent length.

Solving the first-order condition (24) from the R\&D sector and imposing the balanced-growth condition yield the steady-state share of workers in the R\&D sector given by

$$
s_{r}=\lambda \frac{\Omega(T)}{\rho-n}\left(\frac{z-1}{z}\right) \frac{\beta}{\alpha} .
$$

Substituting (20) and (29) into $s_{h}+s_{q}+s_{r}=1$ closes the model by solving for the steady-state share of workers in the homogenous-goods sector given by

$$
s_{h}=1-\frac{\beta}{\alpha}\left(\frac{T \lambda+(1-T \lambda) z}{z}+\lambda \frac{\Omega(T)}{\rho-n}\left(\frac{z-1}{z}\right)\right) .
$$

The per capita supply of homogenous goods is

$$
\alpha s_{h}=\alpha-\beta\left(\frac{T \lambda+(1-T \lambda) z}{z}+\lambda \frac{\Omega(T)}{\rho-n}\left(\frac{z-1}{z}\right)\right) .
$$

From the budget constraints, the steady-state per capita consumption of homogenous goods is

$$
\begin{gathered}
c_{h}(I)=w-P_{q} c_{q}+(\rho-n) a(I)=\alpha-\beta+\frac{\lambda}{\theta}\left(T-\frac{\Omega(T)}{\rho-n}\right)\left(\frac{z-1}{z}\right) \beta, \\
c_{h}(I I)=w-P_{q} c_{q}=\alpha-\beta .
\end{gathered}
$$

Therefore, the following parameter restriction is sufficient to ensure an interior solution for both types of households 


$$
\alpha>\beta
$$

$(\rho-n) a(I)$ is the amount of dividends received by each member of Type-I households, and the total value of financial assets owned by Type-I households equals the market value of all existing patents. From (21), the market value of a pharmaceutical patent that has a remaining life time of $\tau$ years is

$$
V_{t}(\tau)=\frac{\Omega(\tau)}{\rho-n}\left(\frac{z-1}{z}\right) \beta L_{t}
$$

Therefore, the market value of all existing patents in the monopolistic industries is

$$
\frac{\omega}{T} \int_{\tau=0}^{T} V_{t}(\tau) d \tau=\lambda\left(\int_{\tau=0}^{T} \Omega(\tau) d \tau\right)\left(\frac{z-1}{z}\right) \frac{\beta L_{t}}{\rho-n},
$$

where $\left(\int_{\tau=0}^{T} \Omega(\tau) d \tau\right)=\left(T-\frac{\Omega(T)}{\rho-n}\right)$.

To see the conflict of interests across the two types of households, differentiating $c_{h}(I)$ and $c_{h}(I I)$ with respect to $T$ yields

$$
\begin{gathered}
\frac{\partial c_{h}(I)}{\partial T}=\frac{\lambda}{\theta}\left(1-\frac{\Omega^{\prime}(T)}{\rho-n}\right)\left(\frac{z-1}{z}\right) \beta>0, \\
\frac{\partial c_{h}(I I)}{\partial T}=0 .
\end{gathered}
$$

Note that $\Omega^{\prime}(T)=\exp (-(\rho-n) T)(\rho-n)$. An increase in $T$ has three effects on the welfare of each household. (36) and (37) indicate the asymmetric effect coming from the increase in the value of patents that benefits only the patent owners. The two symmetric effects as shown in (17) are the negative effect of markup-pricing distortion and the positive effect of a higher level of pharmaceutical technology.

\subsection{DESIRED PATENT LENGTHS FOR PATENT OWNERS AND CONSUMERS}

Given the equilibrium conditions, the lifetime utility for each type of households along the balanced growth path can be derived by rewriting (1) into 


$$
U(i, T)=\frac{c_{h}(i, T)+\beta \ln c_{q, 0}(T)}{\rho-n}+\int_{0}^{\infty} e^{-(\rho-n) t}(g t) d t,{ }^{19}
$$

for $i \in\{I, I I\} . c_{h}(I, T)$ is a function of $T$ because an increase in patent length raises the value of dividends that increases the consumption of the patent owners. From (17),

$$
\ln c_{q, 0}(T)=\ln A_{0}(T)-T \lambda \ln z+\ln (\beta / \alpha)
$$

$T \lambda \ln z$ is a function of $T$ because an increase in $T$ worsens the markup-pricing distortion by increasing the fraction of monopolistic sub-industries. $\ln A_{0}(T)$ is a function of $T$ because an increase in $T$ enhances the incentives for R\&D, which in turn raises the level of technology for pharmaceuticals. From (27),

$$
A_{0}(T)=\left(\frac{\varphi \ln z}{g}\right)^{1 /(1-\phi)} L_{r, 0}^{\gamma /(1-\phi)}(T)
$$

$\int_{0}^{\infty} e^{-\left(\rho_{i}-n\right) t}(g t) d t$ represents the balanced growth path of $A_{t}$ and is independent of $T$ because of the semiendogenous growth formulation. Substituting (29), (39) and (40) into (38) and dropping some constant terms and the exogenous growth path, the lifetime utility can be further simplified to

$$
U(i, T)=(\rho-n)^{-1}\left(c_{h}(i, T)+\beta\left(\frac{\gamma}{1-\phi}\right) \ln \Omega(T)-\beta T \lambda \ln z\right)
$$

for $i \in\{I, I I\}$. Therefore, the first-order condition that characterizes the desired patent length is

$$
\frac{\partial U(i, T)}{\partial T}=(\rho-n)^{-1}\left(\frac{\partial c_{h}(i, T)}{\partial T}+\beta\left(\frac{\gamma}{1-\phi}\right) \frac{\Omega^{\prime}(T)}{\Omega(T)}-\beta \lambda \ln z\right)=0
$$

for $i \in\{I, I I\}$. Denoted the solution to (42) by $T_{i}^{*}$ for $i \in\{I, I I\}$.

Lemma 1: $T_{I}^{*}>T_{I I}^{*}$.

Proof: Note that $\frac{\partial c_{h}(I, T)}{\partial T}>\frac{\partial c_{h}(I I, T)}{\partial T}=0$ from (36) and (37).

\footnotetext{
${ }^{19}$ The conclusion briefly discusses the generality of a steady-state welfare analysis that ignores transition dynamics.
} 
Intuitively, the patent owners have a longer desired patent length than the consumers because of the asymmetric ownership of patents as financial assets whose market value increases in patent length. This setup leads to a conflict of interest across the two types of households and gives rise to the potential role of the pharmaceutical lobby influencing the government's policy choice through campaign contributions.

\subsection{OPTIMAL PATENT LENGTH}

A benevolent government chooses the patent length to maximize social welfare subject to the equilibrium conditions. Social welfare is defined as

$$
W(T) \equiv \int_{0}^{1} U(i, T) d i=\theta U(I, T)+(1-\theta) U(I I, T) .
$$

The first-order condition that characterizes the optimal patent length is

$$
\frac{\partial W(T)}{\partial T}=\theta \frac{\partial U(I, T)}{\partial T}+(1-\theta) \frac{\partial U(I I, T)}{\partial T}=0
$$

Denote the solution to (44) by $T^{*}$. The second-order condition at the social optimum is

$$
\frac{\partial^{2} W\left(T^{*}\right)}{\partial T^{2}}=-\Omega^{\prime \prime}\left(T^{*}\right) \frac{\beta}{\rho-n}\left(\frac{\gamma}{1-\phi}\right)\left(\frac{n}{\rho-n}\left(\frac{z-1}{z \ln z}\right)-\frac{1}{\Omega\left(T^{*}\right)^{2}}\right)=0 .
$$

The sign of (45) is given by

$$
\operatorname{sign}\left(\frac{\partial^{2} W\left(T^{*}\right)}{\partial T^{2}}\right)=\operatorname{sign}\left(\frac{n}{\rho-n}\left(\frac{z-1}{z \ln z}\right)-\frac{1}{\Omega\left(T^{*}\right)^{2}}\right) .
$$

To ensure that the second-order condition is satisfied for a maximum, the following assumption is imposed on the parameter values

$$
\left(\frac{z \ln z}{z-1}\right)>\frac{n}{\rho-n}
$$

This assumption rules out the possibility that an increase in $T$ would increase $c_{h}(I, T)$ by so much that $T^{*}$ is unbounded. Comparing with (42), (44) is simply a weighted average of the first-order conditions 
for the two types of households. The larger is $\theta$, the closer $T^{*}$ is to $T_{I}^{*}$, and vice versa. Lemma 2 summarizes these findings.

Lemma 2: $T^{*} \in\left(T_{I I}^{*}, T_{I}^{*}\right)$ and $\partial T^{*} / \partial \theta>0$ for $\theta \in(0,1)$.

Proof: Note (42) and (44).

\subsection{CAMPAIGN CONTRIBUTIONS}

This subsection employs the modeling tools in Grossman and Helpman (2001, chapter 7) to model campaign contributions for legislative influence. In addition to social welfare, the government is assumed to value campaign contributions, denoted by $C_{0}$, and its objective function is a weighted average of $W(T)$ and $C_{0}$ given by

$$
\tilde{W}\left(T, C_{0}\right) \equiv(1-\varsigma) W(T)+\varsigma C_{0} \cdot{ }^{20}
$$

$\varsigma \in(0,1]$ is the weight that the government places on campaign contributions. The pharmaceutical lobby and the government are assumed to engage in efficient bargaining and be able to commit to the bargaining outcome on patent length and campaign contributions. The quasi-linear preference enables me to derive the political-equilibrium patent length without imposing further assumptions on the bargaining process. ${ }^{21}$ The efficient bargaining outcome on the patent length can be derived from the constrained maximization problem $\underset{T, C_{0}}{\operatorname{Max}} \tilde{W}\left(T, C_{0}\right)$ subject to $\theta U(I, T)-C_{0} \geq \hat{U}$ for some value of $\hat{U}$. It is in the government's best interest to choose the highest possible $C_{0}$ to make this inequality constraint binding. Therefore, the constraint can be re-expressed as

$$
C_{0}=\theta U(I, T)-\hat{U}
$$

\footnotetext{
${ }^{20}$ Grossman and Helpman (2001, chapter 10) and (2002, chapter 2) show that this objective function represents a proper reduced form of a model with electoral competition.

${ }^{21}$ Although the political-equilibrium patent length can be determined, the amount of campaign contributions cannot be determined unless further assumptions are imposed on the bargaining process. See Proposition 2.
} 
After substituting (48) into (47) and dropping the constant term, the constrained maximization becomes

$$
\underset{T}{\operatorname{Max}} \tilde{W}(T)=\theta U(I, T)+(1-\varsigma)(1-\theta) U(I I, T) .
$$

In other words, when the government values campaign contributions, the pharmaceutical lobby is able to alter the relative weight that the government places on the households' welfare. In particular, a higher value that the government places on campaign contributions leads to a larger relative weight that the government places on Type-I households' welfare. The first-order condition that characterizes the political-equilibrium patent length, denoted by $T^{S I G}(\varsigma)$, is

$$
\frac{\partial \tilde{W}(T)}{\partial T}=\theta \frac{\partial U(I, T)}{\partial T}+(1-\varsigma)(1-\theta) \frac{\partial U(I I, T)}{\partial T}=0
$$

Comparing (44) and (50), $T^{S I G}(\varsigma)>T^{*}$ for $\varsigma \in(0,1]$ and $\partial T^{S I G}(\varsigma) / \partial \varsigma>0$. As the government places a larger weight on campaign contributions, it chooses a longer patent length. As a result, the amount of monopolistic profits generated by the pharmaceutical industry and the value of pharmaceutical patents also increase. This leads to an increase in $R \& D$ investments, reflected by an increase in the fraction of workers in the R\&D sector. Proposition 1 summarizes these results.

Proposition 1: An increase in $\varsigma$ leads to an increase in: (a) $T^{S I G} ;(b) \pi_{q} ;(c) V$; and (d) $s_{r}$.

Proof: For (a), note (50). Then, recall from (28) that $\partial \omega / \partial T=\lambda>0$. For (b), note (19). For (c), note (21). For (d), note (29).

Determining the impact of $\varsigma$ on the equilibrium amount of campaign contributions requires an additional assumption on the bargaining outcome between the government and the pharmaceutical lobby.

Assumption 3: The government and the pharmaceutical lobby maximizes the total surplus, and the constant share of total surplus captured by the government is $\sigma \in[0,1]$. 
Proposition 2: There exists a $\hat{\sigma} \in(0,1)$ such that if and only if $\sigma \geq \hat{\sigma}, \partial C_{0} / \partial \varsigma \geq 0$ for $\varsigma \in(0,1)$.

Proof: See Appendix A.

Corollary 1a: The government having the first-mover advantage to make a take-or-leave-it offer to the SIG is equivalent to $\sigma=1$. In this case, $C_{0}=\theta\left(U\left(I, T^{S I G}\right)-U\left(I, T^{*}\right)\right)$ and $\partial C_{0} / \partial \varsigma>0$ for $\varsigma \in(0,1)$. Proof: See Appendix A.

Corollary 1b: The SIG having the first-mover advantage to make a take-or-leave-it offer to the government is equivalent to $\sigma=0$. In this case, $C_{0}=\left(W\left(T^{*}\right)-W\left(T^{S I G}\right)\right)(1-\varsigma) / \varsigma$ and $\partial C_{0} / \partial \varsigma<0$ for $\varsigma \in(0,1)$.

Proof: See Appendix A.

Intuitively, whether the amount of campaign contributions increases or decreases in response to a larger $\varsigma$ depends on the relative bargaining power between the government and the SIG. When the government has all the bargaining power (i.e. $\sigma=1$ ), it is able to extract all the surplus from the SIG, and hence, $\partial C_{0} / \partial \varsigma>0$. Similarly, when the SIG has all the bargaining power (i.e. $\sigma=0$ ), it contributes the smallest amount possible in order to make the government indifferent between $T^{S I G}$ and $T^{*}$.

\subsection{WELFARE ANALYSIS IN CLOSED VS. OPEN ECONOMY}

Grossman and Lai (2004) and Lai and Qiu (2003) show that the Nash-equilibrium level of patent protection in a multi-country setting is suboptimally low because each country has the incentive to free ride on other countries' innovations. Therefore, when all countries act according to their best response functions in choosing the level of patent protection, the Nash-equilibrium patent length is much shorter than the global optimum. This is a realistic description of the real world because innovations occur 
worldwide. At least, innovations come from multiple industrial countries. Therefore, the closed-economy setting is now extended to a multi-country setting in order to compare the different welfare implications. The theoretical result is that the pharmaceutical lobbies may improve social welfare in the multi-country setting by increasing the patent length from a globally suboptimal level.

There are $N$ symmetric countries. For simplicity, transportation costs are assumed to be zero, and there is no international lending and borrowing as commonly assumed in the literature to pin down a unique trade pattern. When an R\&D entrepreneur has an innovation success, she obtains a patent in each country. Therefore, in addition to the stream of monopolistic profits from the domestic economy, she is also entitled to the profits from abroad. At the aggregate level, these transfers of monopolistic profits for patent services are balanced by an equal value of trade in homogenous goods. The symmetry assumption implies that each country owns an equal fraction of patented innovations in the world.

The two equilibrium concepts for the open-economy model are as follows.

1. Nash Equilibrium. In the absence of lobbying, the benevolent government in each country chooses the patent length to maximize the welfare of its own citizens taking the level of patent protection abroad as given. The resulting first-order condition for each country $s \in\{1, \ldots, N\}$ is a social best response function given by

$$
\frac{\partial W^{s}\left(T^{1}, \ldots, T^{N}\right)}{\partial T^{s}}=\theta \frac{\partial U^{s}\left(I, T^{1}, \ldots, T^{N}\right)}{\partial T^{s}}+(1-\theta) \frac{\partial U^{s}\left(I I, T^{1}, \ldots, T^{N}\right)}{\partial T^{s}}=0
$$

(i.e. the multi-country analog of (44)), and the Nash equilibrium is the solution of the social best response functions of all countries.

2. Political Equilibrium. In the presence of lobbying, the SIG in each country is assumed to lobby its own government taking the action of the SIGs in other countries as given. The resulting first-order condition for each country $s \in\{1, \ldots, N\}$ is a SIG best response function given by

$$
\frac{\partial \tilde{W}^{s}\left(T^{1}, \ldots, T^{N}\right)}{\partial T^{s}}=\theta \frac{\partial U^{s}\left(I, T^{1}, \ldots, T^{N}\right)}{\partial T^{s}}+(1-\varsigma)(1-\theta) \frac{\partial U^{s}\left(I I, T^{1}, \ldots, T^{N}\right)}{\partial T^{s}}=0
$$


(i.e. the multi-country analog of (50)), and the political equilibrium is the solution of the SIG best response functions of all countries.

The followings sketch out the key equations of the multi-country model. The no-arbitrage value of a patent is the present value of the stream of monopolistic profits from all countries $s \in\{1, \ldots, N\}$.

$$
V_{t}=\sum_{s=1}^{N}\left(\int_{\tau=t}^{t+T^{s}} e^{-\rho(\tau-t)} \pi_{q, \tau}^{s}\left(j^{\prime}\right) d \tau\right)=\left(\sum_{s=1}^{N} \Omega\left(T^{s}\right)\right)\left(\frac{z-1}{z}\right) \frac{\beta L_{t}}{\rho-n} .
$$

The statutory patent length in country $s$ is denoted by $T^{s}$. In the Nash equilibrium, $T^{s}$ is the same across countries because of symmetry. The law of motion for technology is

$$
\dot{A}_{t}=A_{t} \bar{\varphi}_{t}\left(\sum_{s=1}^{N} L_{r, t}^{s}\right) \ln z
$$

The first implicit assumption behind (54) is that each country has the immediate access to the technological innovations from abroad, and this is a reasonable assumption because the inventors have the incentive to patent their innovations internationally. The second assumption is that technological innovations across countries are perfect substitutes because of the identical households' preferences across countries, and this is likely to be a reasonable description of the demand for pharmaceuticals in industrial countries. The first-order condition from the R\&D sector becomes

$$
\frac{L_{r, t}^{s}}{L_{t}}=\lambda\left(\sum_{s=1}^{N} \frac{\Omega\left(T^{s}\right)}{N}\right)\left(\frac{z-1}{z}\right) \frac{\beta / \alpha}{\rho-n} .
$$

Using the balanced-growth path condition, the multi-country analog of (40) is

$$
A_{0}\left(T^{1}, \ldots, T^{N}\right)=\left(\frac{\varphi \ln z}{g}\right)^{1 /(1-\phi)}\left(\sum_{s=1}^{N} L_{r, 0}^{s}\left(T^{1}, \ldots, T^{N}\right)\right)^{\gamma /(1-\phi)} .
$$

(55) and (56) reveal one of the two key differences between the closed-economy model and the multicountry model in which a unilateral increase in $T^{s}$ leads to a much smaller percentage increase in 
$\sum_{s=1}^{N} L_{r, 0}^{s}\left(T^{1}, \ldots, T^{N}\right)$ and consequently a much smaller percentage increase in $A_{0}\left(T^{1}, \ldots, T^{N}\right)$. The market value of all existing patents in the global economy at time $t$ is

$$
\sum_{s=1}^{N}\left(\frac{\omega\left(T^{s}\right)}{T^{s}} \int_{\tau=0}^{T^{s}} \Omega(\tau) d \tau\right)\left(\frac{z-1}{z}\right) \frac{\beta L_{t}}{\rho-n}
$$

Therefore, the amount of dividends received by each member of Type-I households in country $s$ is

$$
(\rho-n) a^{s}(I)=\frac{\lambda}{N \theta} \sum_{s=1}^{N}\left(T^{s}-\frac{\Omega\left(T^{s}\right)}{\rho-n}\right)\left(\frac{z-1}{z}\right) \beta .
$$

The derivative of $c_{h}^{s}\left(I, T^{1}, \ldots, T^{N}\right)$ with respect to $T^{s}$ is given by

$$
\frac{\partial c_{h}^{s}\left(I, T^{1}, \ldots, T^{N}\right)}{\partial T^{s}}=\frac{\lambda}{N \theta}\left(1-\frac{\Omega^{\prime}\left(T^{s}\right)}{\rho-n}\right)\left(\frac{z-1}{z}\right) \beta,
$$

which reveals the other key difference that an unilateral increase in $T^{s}$ has a smaller impact on domestic consumption because a large fraction of the increase in monopolistic profits is accrued to foreigners.

The social best response function (51) of country $s \in\{1, \ldots, N\}$ becomes

$$
\theta \frac{\partial c_{h}^{s}\left(I, T^{1}, \ldots, T^{N}\right)}{\partial T^{s}}+\beta\left(\frac{\gamma}{1-\phi}\left(\Omega^{\prime}\left(T^{s}\right) / \sum_{s=1}^{N} \Omega\left(T^{s}\right)\right)-\lambda \ln z\right)=0
$$

By imposing symmetry, the condition that characterizes the symmetric Nash-equilibrium patent length $T^{N E}$ simplifies to

$$
\frac{\Omega^{\prime}\left(T^{N E}\right)}{\Omega\left(T^{N E}\right)}=n\left(N-\Omega\left(T^{N E}\right)\left(\frac{z-1}{z \ln z}\right)\right) .
$$

Lemma 3: The Nash-equilibrium patent length is decreasing in $N$ and is strictly below the symmetric globally optimal patent length when the number of countries is at least two.

Proof: See Appendix A. 
In the case of special interest politics, the SIG best response function (52) of country $s \in\{1, \ldots, N\}$ becomes

$$
\theta \frac{\partial c_{h}^{s}\left(I, T^{1}, \ldots, T^{N}\right)}{\partial T^{s}}+(1-\varsigma(1-\theta)) \beta\left(\frac{\gamma}{1-\phi}\left(\Omega^{\prime}\left(T^{s}\right) / \sum_{s=1}^{N} \Omega\left(T^{s}\right)\right)-\lambda \ln z\right)=0
$$

The condition that characterizes the symmetric political-equilibrium patent length $T^{S I G}$ simplifies to

$$
\frac{\Omega^{\prime}\left(T^{S I G}\right)}{\Omega\left(T^{S I G}\right)}=n\left(N-\Omega\left(T^{S I G}\right)\left(\frac{z-1}{z \ln z}\right) \frac{1}{1-\varsigma(1-\theta)}\right) \text {. }
$$

Proposition 3: When $N=1, W\left(T^{S I G}\right)<W\left(T^{*}\right)$ for $\varsigma \in(0,1]$. When $N \geq 2$, there exists a $\hat{\varsigma}$ such that for $\varsigma \in(0, \hat{\zeta}], W^{s}\left(T^{S I G}\right)>W^{s}\left(T^{N E}\right)$, and $\hat{\zeta}$ is increasing in $N$. Furthermore, for any given $\tilde{\zeta} \in(0,1)$, there exists a $\tilde{N}$ such that if $N \geq \tilde{N}, U^{s}\left(I I, T^{S I G}\right)>U^{s}\left(I I, T^{N E}\right)$.

Proof: See Appendix A.

Proposition 3 shows that the pharmaceutical lobbies may improve social welfare when the level of patent protection is not chosen optimally by the government such as in the case of a multi-country Nash equilibrium. Figure 1 illustrates the intuition of Proposition 3 in a two-country setting. Furthermore, the pharmaceutical lobby may even improve the welfare of the consumers (i.e. Type-II households) when the degree of international free-riding on innovations is severe enough.

Proposition 3 also shows that in a multi-country setting, the presence of a symmetric SIG may improve the social welfare of each country. However, if the SIGs have asymmetric influences across countries, then the country, in which the government places a higher value on campaign contributions, would gain by less or even suffer a welfare loss compared to the symmetric Nash equilibrium. Proposition 4 proves this statement in a two-country setting. 
Proposition 4: Suppose that at the symmetric political equilibrium with $\varsigma^{1}=\varsigma^{2}=\widehat{\varsigma}>0$, both countries are better off compared to the symmetric Nash equilibrium. Then, there must exist a $\breve{\zeta} \in(0, \widehat{\zeta})$ such that when $\varsigma^{1}=\widehat{\zeta}$ and $\varsigma^{2} \in[0, \breve{\zeta}]$, country 1 is worse off compared to the symmetric Nash equilibrium.

\section{CONCLUSION}

Since the 80 's, the pharmaceutical industry has benefited substantially from a series of policy changes that have strengthened the patent protection for brand-name drugs as a result of the industry's political influence, which potentially comes from lobbying and campaign contributions. This paper incorporates special interest politics into a quality-ladder growth model to analyze the policymakers' tradeoff between the socially optimal patent length and campaign contributions. The welfare analysis suggests that the presence of a pharmaceutical lobby distorting the level of patent protection is socially undesirable in a closed-economy setting. However, in a multi-country setting, the presence of a symmetric SIG may improve the social welfare of each country. If the SIGs have asymmetric influences across countries, then the country that has a more politically influential SIG would gain by less or even suffer a welfare loss. It remains as an empirical question as to whether the pharmaceutical lobby in the US is more or less politically influential than its foreign counterparts.

Before closing the paper, I briefly discuss the generality of the steady-state welfare analysis. The transition dynamics is omitted for analytical tractability; however, the theoretical predictions should be robust for two reasons. Firstly, the government may want to maximize social welfare that includes the transition dynamics. So long as there is a positive externality in patent protection, the Nash-equilibrium patent length is globally suboptimal. Thus, an increase in patent length due to political influences may still improve social welfare. Secondly, the resource reallocation from production to R\&D as a result of increasing patent protection does not necessarily lead to short-run consumption losses. ${ }^{22}$ In this case, improving steady-state welfare would be sufficient to improve social welfare.

\footnotetext{
${ }^{22}$ E.g. Chu (2007) shows that this result holds true over a range of parameters in a model with capital accumulation.
} 


\section{APPENDIX A}

Proposition 2: There exists a $\hat{\sigma} \in(0,1)$ such that if and only if $\sigma \geq \hat{\sigma}, \partial C_{0} / \partial \varsigma \geq 0$ for $\varsigma \in(0,1)$.

Proof: The welfare of the government is firstly rescaled so that one dollar for the government has the same utility weight as one dollar for the SIG. Dividing (47) by $\varsigma$,

$$
\tilde{W}\left(T, C_{0}\right) / \varsigma=W(T)(1-\varsigma) / \varsigma+C_{0}
$$

The total surplus of the government and the SIG at $T^{S I G}$ is

$$
T S=\left[W\left(T^{S I G}\right)-W\left(T^{*}\right)\right](1-\varsigma) / \varsigma+\theta\left[U\left(I, T^{S I G}\right)-U\left(I, T^{*}\right)\right] .
$$

Differentiating (a2) with respect to $T$ yields

$$
\frac{\partial T S}{\partial T}=\left(\frac{1-\varsigma}{\varsigma}\right) \frac{\partial W\left(T^{S I G}\right)}{\partial T}+\theta \frac{\partial U\left(I, T^{S I G}\right)}{\partial T}=0
$$

Multiplying (a3) by $\varsigma$ and substituting (44) into (a3) yields the same first-order condition as (50). From Assumption 3, the amount of surplus captured by the government is $\sigma T S$ such that

$$
\left[W\left(T^{S I G}\right)-W\left(T^{*}\right)\right](1-\varsigma) / \varsigma+C_{0}=\sigma T S
$$

Rearranging some terms, (a4) becomes

$$
C_{0}=(\sigma-1)\left[W\left(T^{S I G}\right)-W\left(T^{*}\right)\right](1-\varsigma) / \varsigma+\sigma \theta\left[U\left(I, T^{S I G}\right)-U\left(I, T^{*}\right)\right]
$$

Differentiating (a5) with respect to $\varsigma$ yields

$$
\frac{\partial C_{0}}{\partial \varsigma}=\frac{\sigma-1}{\varsigma}\left(\left[W\left(T^{*}\right)-W\left(T^{S I G}\right)\right] \frac{1}{\varsigma}+\frac{\partial W\left(T^{S I G}\right)}{\partial \varsigma}(1-\varsigma)\right)+\sigma \theta \frac{\partial U\left(I, T^{S I G}\right)}{\partial \varsigma}
$$

Note that $W\left(T^{*}\right)-W\left(T^{S I G}\right)>0, \partial W\left(T^{S I G}\right) / \partial \varsigma<0$, and $\partial U\left(I, T^{S I G}\right) / \partial \varsigma>0$. The next step is to show that there exists a unique $\hat{\sigma} \in(0,1)$ such that $\partial C_{0} / \partial \varsigma_{\sigma=\hat{\sigma}}=0$. I will show this in three steps: (i) $\partial^{2} C_{0} / \partial \varsigma \partial \sigma>0 ;$ (ii) $\partial C_{0} /\left.\partial \varsigma\right|_{\sigma=0}<0$; and (iii) $\partial C_{0} /\left.\partial \varsigma\right|_{\sigma=1}>0$ 


$$
\frac{\partial C_{0}}{\partial \varsigma \partial \sigma}=\frac{1}{\varsigma}\left(\left[W\left(T^{*}\right)-W\left(T^{S I G}\right)\right] \frac{1}{\varsigma}+\frac{\partial W\left(T^{S I G}\right)}{\partial \varsigma}(1-\varsigma)\right)+\theta \frac{\partial U\left(I, T^{S I G}\right)}{\partial \varsigma}>0
$$

Note that $\left[W\left(T^{*}\right)-W\left(T^{S I G}\right)\right] / \varsigma+(1-\varsigma) \partial W\left(T^{S I G}\right) / \partial \varsigma>0$ because $1 / \varsigma>(1-\varsigma)$ for $\varsigma \in(0,1)$ and

$$
\begin{aligned}
& {\left[W\left(T^{*}\right)-W\left(T^{S I G}\right)\right]>-\partial W\left(T^{S I G}\right) / \partial \varsigma} \\
& \left.\frac{\partial C_{0}}{\partial \varsigma}\right|_{\sigma=0}=-\frac{1}{\varsigma}\left(\left[W\left(T^{*}\right)-W\left(T^{S I G}\right)\right] \frac{1}{\varsigma}+\frac{\partial W\left(T^{S I G}\right)}{\partial \varsigma}(1-\varsigma)\right)<0 . \\
& \left.\frac{\partial C_{0}}{\partial \varsigma}\right|_{\sigma=1}=\theta \frac{\partial U\left(I, T^{S I G}\right)}{\partial \varsigma}>0 .
\end{aligned}
$$

Thus, there must exist a $\hat{\sigma} \in(0,1)$ such that if and only if $\sigma \geq \hat{\sigma}, \partial C_{0} / \partial \varsigma \geq 0$ for $\varsigma \in(0,1)$.

Corollary 1a: The government having the first-mover advantage to make a take-or-leave-it offer to the SIG is equivalent to $\sigma=1$. In this case, $C_{0}=\theta\left(U\left(I, T^{S I G}\right)-U\left(I, T^{*}\right)\right)$ and $\partial C_{0} / \partial \varsigma>0$ for $\varsigma \in(0,1)$.

Proof: At the social optimum $T^{*}$, the welfare of the SIG is

$$
\theta U\left(I, T^{*}\right)
$$

In the political equilibrium $\left\{T^{S I G}, C_{0}\right\}$, the welfare of the SIG is

$$
\theta U\left(I, T^{S I G}\right)-C_{0}
$$

Therefore, the maximum amount that the SIG is willing to pay as campaign contributions is the amount for which it is indifferent between $\left\{T, C_{0}\right\}=\left\{T^{*}, 0\right\}$ and $\left\{T, C_{0}\right\}=\left\{T^{S I G}, \theta\left(U\left(I, T^{S I G}\right)-U\left(I, T^{*}\right)\right)\right\}$. Therefore, the participation constraint is

$$
C_{0} \leq \theta\left(U\left(I, T^{S I G}\right)-U\left(I, T^{*}\right)\right)
$$

Since the government has the first-mover advantage, it would make an offer to the SIG such that the participation constraint is binding. Note that setting $\sigma=1$ in (a5) yields 


$$
C_{0}=\theta\left[U\left(I, T^{S I G}\right)-U\left(I, T^{*}\right)\right]
$$

Therefore, $\sigma=1$ is equivalent to the case in which the government has the first-mover advantage to make a take-or-leave-it offer to the SIG. In this case, $\partial C_{0} / \partial \varsigma>0$ for $\varsigma \in(0,1)$ as shown in (a9).

Corollary 1b: The SIG having the first-mover advantage to make a take-or-leave-it offer to the government is equivalent to $\sigma=0$. In this case, $C_{0}=\left(W\left(T^{*}\right)-W\left(T^{S I G}\right)\right)(1-\varsigma) / \varsigma$ and $\partial C_{0} / \partial \varsigma<0$ for $\varsigma \in(0,1)$.

Proof: At the social optimum $T^{*}$, the welfare of the government is

$$
W\left(T^{*}\right)(1-\varsigma) / \varsigma
$$

In the political equilibrium $\left\{T^{S I G}, C_{0}\right\}$, the welfare of the government is

$$
W\left(T^{S I G}\right)(1-\varsigma) / \varsigma+C_{0}
$$

Therefore, the minimum amount that the government is willing to accept as campaign contributions to implement $T^{S I G}$ is the amount for which it is indifferent between $\left\{T, C_{0}\right\}=\left\{T^{*}, 0\right\}$ and $\left\{T, C_{0}\right\}=\left\{T^{S I G},\left[W\left(T^{*}\right)-W\left(T^{S I G}\right)\right](1-\varsigma) / \varsigma\right\}$. Therefore, the participation constraint is

$$
C_{0} \geq\left[W\left(T^{*}\right)-W\left(T^{S I G}\right)\right](1-\varsigma) / \varsigma
$$

Since the SIG has the first-mover advantage, it would make an offer to the government such that the participation constraint is binding. Note that setting $\sigma=0$ in (a5) yields

$$
C_{0}=\left[W\left(T^{*}\right)-W\left(T^{S I G}\right)\right](1-\varsigma) / \varsigma .
$$

Therefore, $\sigma=0$ is equivalent to the case in which the SIG has the first-mover advantage to make a takeor-leave-it offer to the government. In this case, $\partial C_{0} / \partial \varsigma<0$ for $\varsigma \in(0,1)$ as shown in (a8). 
Lemma 3: The Nash-equilibrium patent length is decreasing in $N$ and is strictly below the symmetric globally optimal patent length when the number of countries is at least two.

Proof: Recall that $T^{N E}$ is characterized by

$$
\frac{\Omega^{\prime}\left(T^{N E}\right)}{\Omega\left(T^{N E}\right)}=n\left(N-\Omega\left(T^{N E}\right)\left(\frac{z-1}{z \ln z}\right)\right) .
$$

Taking the total differentials of (a18), $\operatorname{sign}\left(\frac{d T^{N E}}{d N}\right)=\operatorname{sign}\left(\frac{n}{\rho-n}\left(\frac{z-1}{z \ln z}\right)-\frac{1}{\Omega\left(T^{N E}\right)^{2}}\right)$, which is negative by (A4). The symmetric globally optimal patent length, denoted by $T^{G O}$, is characterized by

$$
\frac{\Omega^{\prime}\left(T^{G O}\right)}{\Omega\left(T^{G O}\right)}=n\left(1-\Omega\left(T^{G O}\right)\left(\frac{z-1}{z \ln z}\right)\right) .
$$

Therefore, for $N \geq 2, T^{N E}<T^{G O}$.

Proposition 3: When $N=1, W\left(T^{S I G}\right)<W\left(T^{*}\right)$ for $\varsigma \in(0,1]$. When $N \geq 2$, there exists a $\hat{\zeta}$ such that for $\varsigma \in(0, \hat{\zeta}], W^{s}\left(T^{S I G}\right)>W^{s}\left(T^{N E}\right)$, and $\hat{\zeta}$ is increasing in $N$. Furthermore, for any given $\tilde{\zeta} \in(0,1)$, there exists a $\tilde{N}$ such that if $N \geq \tilde{N}, U^{s}\left(I I, T^{S I G}\right)>U^{s}\left(I I, T^{N E}\right)$.

Proof: Recall that the symmetric SIG patent length $T^{S I G}$ is characterized by

$$
\frac{\Omega^{\prime}\left(T^{S I G}\right)}{\Omega\left(T^{S I G}\right)}=n\left(N-\Omega\left(T^{S I G}\right)\left(\frac{z-1}{z \ln z}\right) \frac{1}{1-\varsigma(1-\theta)}\right) .
$$

Equating (a19) and (a20) yields

$$
(N-1)=\frac{\varsigma(1-\theta)}{1-\varsigma(1-\theta)} \Omega\left(T^{G O}\right)\left(\frac{z-1}{z \ln z}\right),
$$


where $T^{G O}$ is determined by (a19) and is independent of $N$. Denote the value of $\varsigma$ that solves (a21) by $\hat{\zeta}$. When $N=1, \hat{\zeta}$ must equal zero for (a21) to hold. When $N \geq 2, \hat{\zeta}>0$ and $\partial \hat{\zeta} / \partial N>0$. Note that when $\varsigma>\hat{\zeta}$, it is not necessarily true that $W^{s}\left(T^{S I G}\right)<W^{s}\left(T^{N E}\right)$. In this case, it simply involves the comparison of two globally suboptimal levels of patent protection $T^{N E}$ and $T^{S I G}(\varsigma)$.

To show that even Type-II households may benefit from the pharmaceutical lobbies, (42) implies that the symmetric desired patent length for Type-II households is given by

$$
\frac{\Omega^{\prime}\left(T_{I I}^{*}\right)}{\Omega\left(T_{I I}^{*}\right)}=n
$$

Equating (a22) and (a18) yields

$$
(N-1)=\Omega\left(T^{N E}\right)\left(\frac{z-1}{z \ln z}\right) .
$$

The left-hand side is increasing in $N$ while the right-hand side is decreasing is decreasing in $N$. Therefore, there exists a unique $N$ for which the Nash-equilibrium patent length coincides with the symmetric desired patent length of Type-II households. When the number of countries exceeds this threshold, even Type-II households would find the Nash-equilibrium patent length too short. Finally, equating (a22) and (a20) yields

$$
(N-1)=\frac{1}{1-\varsigma(1-\theta)} \Omega\left(T_{I I}^{*}\right)\left(\frac{z-1}{z \ln z}\right) .
$$

Denote the value of $\varsigma$ that solves (a24) by $\widetilde{\zeta}$. For any given $\tilde{\zeta} \in(0,1)$, there exists a $\tilde{N}$ such that (a24) holds. In this case, $T^{S I G}$ coincides with $T_{I I}^{*}$.

Proposition 4: Suppose that at the symmetric political equilibrium with $\varsigma^{1}=\varsigma^{2}=\widehat{\varsigma}>0$, both countries are better off compared to the symmetric Nash equilibrium. Then, there must exist a $\breve{\zeta} \in(0, \widehat{\zeta})$ such that when $\varsigma^{1}=\widehat{\zeta}$ and $\varsigma^{2} \in[0, \breve{\zeta}]$, country 1 is worse off compared to the symmetric Nash equilibrium. 
Proof: The SIG best response function for country $s \in\{1,2\}$ is

$$
\frac{\lambda \Omega\left(T^{s}\right)}{2}\left(\frac{z-1}{z}\right) \beta+\left(1-\varsigma^{s}(1-\theta)\right) \beta\left(\frac{\gamma}{1-\phi}\left(\frac{\Omega^{\prime}\left(T^{s}\right)}{\Omega\left(T^{1}\right)+\Omega\left(T^{2}\right)}\right)-\lambda \ln z\right)=0 .
$$

The best response function shows that $T^{1}$ and $T^{2}$ are strategic substitutes and $\partial T^{s} / \partial \varsigma^{s}>0$. Therefore, the political-equilibrium pairs of patent length are $T^{1}\left(\varsigma_{+}^{1}, \varsigma_{-}^{2}\right)$ and $T^{2}\left(\varsigma_{-}^{1}, \varsigma_{+}^{2}\right)$.

Suppose that at the symmetric political equilibrium $\left(T^{S I G}, T^{S I G}\right)$ with $\varsigma^{1}=\varsigma^{2}=\widehat{\varsigma}>0$, both countries are better off compared to the symmetric Nash equilibrium $\left(T^{N E}, T^{N E}\right)$. We know from Proposition 3 that such $\widehat{\zeta}$ always exists. At $\varsigma^{1}=\widehat{\zeta}$ and $\varsigma^{2}=0, T^{1}>T^{S I G}$ and $T^{2}<T^{N E}$. Therefore, there must exist a $\breve{\zeta} \in(0, \widehat{\zeta})$ such that when $\varsigma^{1}=\widehat{\zeta}$ and $\varsigma^{2}=\breve{\zeta}, T^{2}=T^{N E}$. At this point, the social best response of country 1 is to set $T^{1}=T^{N E}$, but it is setting $T^{1}>T^{S I G}>T^{N E}$. Therefore, it must be worse off compared to the symmetric Nash equilibrium. Finally, if country 1 is worse off at $\varsigma^{2}=\breve{\zeta}$, it must also be worse off for $\varsigma^{2} \in[0, \breve{\zeta}]$. 


\section{Figure 1: Nash Equilibrium vs. Political Equilibrium}

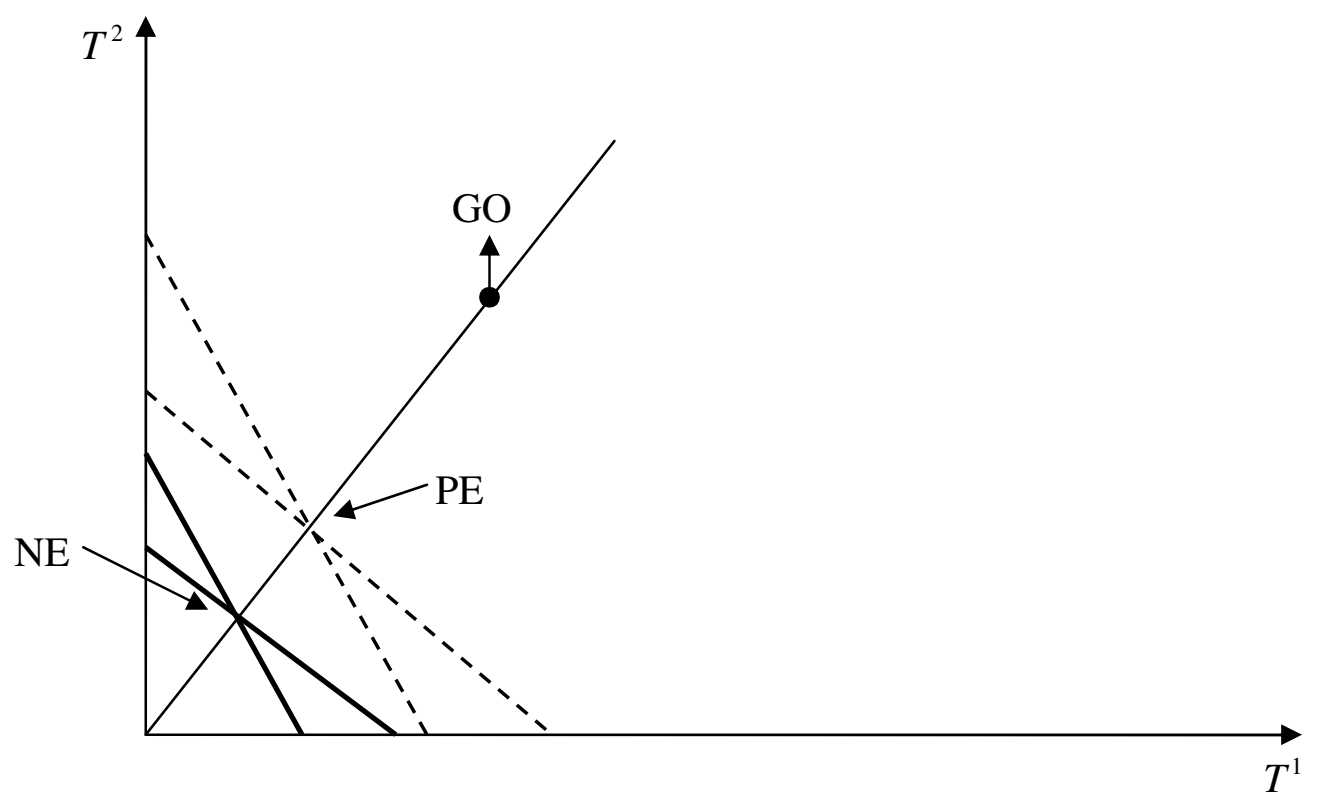

1. NE refers to the Nash-equilibrium patent length, and the bold lines are the social best response functions of country 1 and country 2 .

2. PE refers to the political-equilibrium patent length, and the dotted lines are the SIG best response functions of country 1 and country 2 .

3. GO refers to the symmetric globally optimal patent length. 


\section{REFERENCES}

Aghion, P. and P. Howitt, 1992, A model of growth through creative destruction. Econometrica 60, 323351.

Angell, M., 2005, The truth about the drug companies: how they deceive us and what to do about it (Random House, New York).

Ansolabehere, S., J. M. de Figueiredo and J. M. Snyder, 2003, Why is there so little money in U.S. politics. Journal of Economic Perspectives 17, 105-130.

Becker, G. S., 1983, A theory of competition among pressure groups for political influence. Quarterly Journal of Economics 98, 371-400.

Besley, T. and S. Coate, 2001, Lobbying and welfare in a representative democracy. Review of Economics Studies 68, 67-82.

Coate, S. and S. Morris, 1999, Policy persistence. American Economic Review 89, 1327-1336.

Chu, A. C., 2007, Optimal patent breadth: quantifying the effects of patent breadth and blocking patent. University of Michigan Working Paper.

Dinopoulos, E., A. Gungoraydinoglu and C. Syropoulos, 2005, Patent protection and global Schumpeterian growth, in: E. Dinopoulos, P. Krishna, A. Panagariya and K. Wong, eds., Globalization: prospects and problems; papers in honor of Jagdish Bhagwati (Routledge, New York).

Drazen, A., 2000, Political economy in macroeconomics (Princeton University Press, Princeton, NJ).

Eisenberg, R. S., 2001, The shifting functional balance of patents and drug regulation. Health Affairs 19, 119-135.

Feenstra, R. C., 2004, Advanced international trade: theory and evidence (Princeton University Press, Princeton, NJ).

Gallini, N. T., 2002, The economics of patents: lessons from recent U.S. patent reform. Journal of Economic Perspectives 16, 131-154. 
Gilbert, R. and C. Shapiro, 1990, Optimal patent length and breadth. RAND Journal of Economics 21, 106-112.

Grossman, G. M. and E. Helpman, 1991, Quality ladders in the theory of growth. Review of Economic Studies 58, 43-61.

Grossman, G. M. and E. Helpman, 1994, Protection for sale. American Economic Review 84, 833-850.

Grossman, G. M. and E. Helpman, 2001, Special interest politics (MIT Press, Cambridge, MA).

Grossman, G. M. and E. Helpman, 2002, Interest groups and trade policy (Princeton University Press, Princeton, NJ).

Grossman, G. M. and E. Lai, 2004, International protection of intellectual property. American Economic Review 94, 1635-1653.

Helpman, E. and T. Persson, 2001, Lobbying and legislative bargaining. Advances in Economic Analysis \& Policy 1 , article 3 .

Jaffe, A. B., 2000, The U.S. patent system in transition: policy innovation and the innovation process. Research Policy 29, 531-557.

Jones, C. I., 1995a, Time series tests of endogenous growth models. Quarterly Journal of Economics 110, 495-525.

Jones, C. I., 1995b, R\&D-based models of economic growth. Journal of Political Economy 103, 759-784.

Jones, C. I., 1999, Growth: with or without scale effects. American Economic Review Papers and Proceedings 89, 139-144.

Jones, C. I., 2002, Sources of U.S. economic growth in a world of ideas. American Economic Review 92, 220-239.

Judd, K. L., 1985, On the performance of patents. Econometrica 53, 567-586.

Krueger, A. O., 1974, The political economy of the rent-seeking society. American Economic Review 64, 291-303.

Krusell, P. and J. Rios-Rull, 1996, Vested interests in a positive theory of stagnation and growth. Review of Economic Studies 63, 301-329. 
Lai, E., 2005, Was global patent protection too weak before TRIPS?. City University of Hong Kong Working Paper.

Lai, E. and L. D. Qiu, 2003, The North's intellectual property rights standard for the South?. Journal of International Economics 59, 183-209.

Mitra, D., 1999, Endogenous lobby formation and endogenous protection: a long run model of trade policy determination. American Economic Review 89, 1116-1134.

National Institute for Health Care Management Foundation, 2000, Prescription drugs and intellectual property protection: finding the right balance between access and innovation.

Nordhaus, W., 1969, Invention, growth, and welfare (MIT Press, Cambridge, MA).

North, D. C., 2005, Understanding the process of economic change (Princeton University Press, Princeton, NJ).

O'Donoghue, T. and J. Zweimuller, 2004, Patents in a model of endogenous growth. Journal of Economic Growth 9, 81-123.

Persson, T. and G. Tabellini, 2000, Political economics: explaining economic policy (MIT Press, Cambridge, MA).

Posner, R. A., 1975, The social costs of monopoly regulation. Journal of Political Economy 83, 807-828.

Scotchmer, S., 2004, Innovation and incentives (MIT Press, Cambridge, MA).

Segerstrom, P. S., 1998, Endogenous growth without scale effects. American Economic Review 88, 12901310

Snyder, J. M. Jr., 1990, Campaign contributions as investments: the U.S. House of Representatives, 19801986. Journal of Political Economy 98, 1195-1227. 